Tropical Journal of Pharmaceutical Research November 2021; 20 (11): 2267-2272

ISSN: $1596-5996$ (print); 1596-9827 (electronic)

(C) Pharmacotherapy Group, Faculty of Pharmacy, University of Benin, Benin City, 300001 Nigeria

Original Research Article

http://dx.doi.org/10.4314/tjpr.v20i11.5

\title{
Oxymatrine inhibits proliferation and migration of breast cancer cells by inhibiting miRNA-188 and upregulating its target gene, PTEN
}

\author{
Xiaoying Ma1, Zijiang Sang1, Qinghua Zhang'2, Wenbiao $\mathbf{M a}^{1 *}$ \\ ${ }^{1}$ Surgical Oncology Ward 2 (Breast and Thyroid Surgery), ${ }^{2}$ Department of Interventional Ultralsound, Qinghai Provincial \\ People's Hospital, Xining, China \\ *For correspondence: Email: MWBLJ@163.com; Tel: +86-0971-8065169
}

Sent for review: 30 July 2021

Revised accepted: 25 October 2021

\begin{abstract}
Purpose: To explore the potential biological functions of oxymatrine on breast cancer (BCa) cells and the underlying molecular mechanism.

Methods: Relative levels of microRNA-188 (miRNA-188) and PTEN (gene of phosphate and tension homology deleted on chromosome ten) in BCa cells, MDA-MB-231 and TB549, were determined. The influence of oxymatrine treatment, miRNA-188 and PTEN on proliferative and migratory abilities in $B C a$ cells were assessed by 3-(4,5-dimethylthiazol-2-yl)-2,5-diphenyl tetrazolium bromide (MTT), cell counting kit-8 (CCK-8) and Transwell assay, respectively. The binding relationship between miRNA-188 and PTEN was evaluated by dual-luciferase reporter gene assay.

Results: Oxymatrine downregulated miRNA-188 and upregulated PTEN in BCa cells. Proliferative and migratory activities in BCa were inhibited by treatment of oxymatrine $(p<0.05)$. Dual-luciferase reporter gene assay results indicated that PTEN was the target gene of miRNA-188. Furthermore, rescue experiments demonstrated that the regulatory loop, oxymatrine/miRNA-188/PTEN, was involved in the regulation of the migration and proliferation of $\mathrm{BCa}$.

Conclusion: Oxymatrine treatment inhibits BCa progression by downregulating miRNA-188, leading to the upregulation of PTEN. The results of the current study may provide new insight into the diagnosis and treatment of $B C a$.
\end{abstract}

Keywords: Breast cancer, Oxymatrine, MicroRNAs, Signaling pathway, Proliferation, Migration

\begin{abstract}
This is an Open Access article that uses a funding model which does not charge readers or their institutions for access and distributed under the terms of the Creative Commons Attribution License (http://creativecommons.org/licenses/by/4.0) and the Budapest Open Access Initiative (http://www.budapestopenaccessinitiative.org/read), which permit unrestricted use, distribution, and reproduction in any medium, provided the original work is properly credited.

Tropical Journal of Pharmaceutical Research is indexed by Science Citation Index (SciSearch), Scopus, International Pharmaceutical Abstract, Chemical Abstracts, Embase, Index Copernicus, EBSCO, African Index Medicus, JournalSeek, Journal Citation Reports/Science Edition, Directory of Open Access Journals (DOAJ), African Journal Online, Bioline International, Open-J-Gate and Pharmacy Abstracts
\end{abstract}

\section{INTRODUCTION}

Breast cancer $(\mathrm{BCa})$ is the second leading malignancy globally, and about one-eighth of females suffer from $\mathrm{BCa}$ [1]. Annually, $\mathrm{BCa}$ affects 1.3 million women, and it ranks at $23 \%$ of cancer cases and $14 \%$ of cancer deaths [2]. A therapeutic strategy for metastatic breast cancer
(MBC) is limited. About $5 \%$ of $\mathrm{BCa}$ patients develop distant metastases at the time of diagnosis [2,3]. It is necessary to clarify mechanisms underlying the tumorigenesis and tumor progression of $\mathrm{BCa}$, thus improving diagnostic accuracy and prognosis of $\mathrm{BCa}$ patients. 
Accumulated evidence has identified critical functions of microRNA (miRNAs) in human diseases [4]. Abnormally expressed miRNAs are closely linked to the occurrence and progression of cancers $[5,6]$. In $\mathrm{BCa}$, dysregulated miRNAs are able to affect tumor cell behavior, thereby mediating tumor progression [7]. A previous study demonstrated that miRNAs serve as biological markers and therapeutic tools for $\mathrm{BCa}$ [8]. Determination of miRNA levels helps to classify subtypes of $\mathrm{BCa}$ and evaluate therapeutic outcomes [9]. MicroRNAs can be utilized as non-invasive tool for effectively monitoring disease progression in $\mathrm{BCa}[9,10]$.

The aim of the present study was to determine the potential influence of oxymatrine on the biological activities of breast cancer (BCa) cells as well as the underlying mechanism of action.

\section{EXPERIMENTAL}

\section{Cell culture and transfection}

The MDA-MB-231 and TB549 cells were purchased from American Type Culture Collection (ATCC) (Manassas, VA, USA). The cells were cultured at $37{ }^{\circ} \mathrm{C}$ in Roswell Park Memorial Institute 1640 (RPMI 1640) (HyClone, South Logan, UT, USA) containing $10 \%$ fetal bovine serum (FBS) (HyClone, South Logan, UT, USA), $100 \mathrm{U} / \mathrm{mL}$ penicillin and $100 \mathrm{mg} / \mathrm{mL}$ streptomycin in an incubator with $5 \% \mathrm{CO}_{2}$. The cells were inoculated into 6 -well plates and cultured overnight. Transfection was conducted using Lipofectamine 2000 (Invitrogen, Carlsbad, CA, USA).

MTT (3-(4, 5-dimethylthiazol-2-yl)-2,5-diphenyl tetrazolium bromide) assay

The cells were prepared to suspension with $2 \times 10^{4} / \mathrm{mL}$ and applied into 96 -well plates. At the appointed time points, cells were reacted with 20 $\mu \mathrm{L}$ of MTT solution ( $5 \mathrm{mg} / \mathrm{mL}$ ) (Sigma-Aldrich, St. Louis, MO, USA) per well for 4 hours.
Afterwards, medium was replaced and $150 \mu \mathrm{L}$ of dimethyl sulfoxide (DMSO) (Sigma-Aldrich, St. Louis, MO, USA) was added. The mixture was shaken at a low speed for $10 \mathrm{~min}$ to dissolve the Formazan crystals. Absorbance was determined at $450 \mathrm{~nm}$ with an enzyme-linked immunosorbent detector. Each experiment was repeated in triplicate.

\section{Cell counting kit-8 (CCK-8) assay}

The cells were inoculated into 96-well plates using $3.0 \times 10^{3}$ cells per well. At the appointed time points, $10 \mu \mathrm{L}$ of CCK-8 solution (Dojindo, Kumamoto, Japan) was added into each well. The absorbance of each sample was read at 450 $\mathrm{nm}$ in a microplate reader.

\section{Transwell assay}

Cells were prepared in suspension of $1 \times 10^{5}$ cells $/ \mathrm{mL}$. An aliquot of $100 \mu \mathrm{L}$ of suspension was applied in the upper side of Transwell chamber (Corning, Corning, NY, USA). In the bottom side, $500 \mu \mathrm{L}$ of medium containing $20 \%$ FBS was applied. After $48 \mathrm{~h}$ of incubation, cells penetrated to the bottom side were fixed in methanol for 15 min, stained with crystal violet for $20 \mathrm{~min}$ and counted using a microscope. Migratory cell number was counted in 5 randomly selected fields per sample (magnification 200x).

\section{Quantitative real-time polymerase chain reaction (qRT-PCR)}

Extraction of total RNA in cells was performed using TRIzol reagent (Invitrogen, Carlsbad, CA, USA). The RNA was subjected to reverse transcription, and the complementary deoxyribose nucleic acid (cDNA) was applied for PCR using SYBR Green method (TaKaRa, Tokyo, Japan). The U6 was considered as the internal reference. Primer sequences were synthesized by Invitrogen Co., Ltd. (Carlsbad, CA, USA). The primer sequences used are listed in Table 1.

Table 1: Primer sequences used in PCR

\begin{tabular}{lll}
\hline Gene & Primer sequence \\
\hline miRNA-188 & Forward $\left(5^{\prime}>3^{\prime}\right)$ & ACACTCCAGCTGGGTGGGAGGTGGTACGTT \\
& Reverse $\left(5^{\prime}>3^{\prime}\right)$ & CTCAACTGGTGTCGTGGAGTCGGCAATTCA \\
GAPDH & Forward $\left(5^{\prime}>3^{\prime}\right)$ & GAAGGAGAGACCCTCACGCTG \\
& Reverse $\left(5^{\prime}>3^{\prime}\right)$ & ACTGTGAGGAGGGGAGATTCAGT \\
PTEN & Forward $\left(5^{\prime}>3^{\prime}\right)$ & GGTGGGTTATGGTCTTCAAAAGG \\
& Reverse $\left(5^{\prime}>3^{\prime}\right)$ & CTCGCTTCGGCAGCAGCACATATA \\
U6 & Forward $\left(5^{\prime}>3^{\prime}\right)$ & AAATATGGAACGCTTCACGA \\
& Reverse $\left(5^{\prime}>3^{\prime}\right)$ &
\end{tabular}




\section{Dual-luciferase reporter gene assay}

PTEN-3'UTR-MUT and PTEN-3'UTR-WT luciferase vectors were constructed based on the binding sites in promoter regions of miRNA-188 and PTEN. The cells were co-transfected with miRNA-188 mimics/NC and PTEN WT/PTEN MUT. After $48 \mathrm{~h}$ transfection, the cells were lysed for the determination of relative luciferase activity (Promega, Madison, WI, USA).

\section{Statistical analysis}

IBM SPSS 18.0 software (IBM Inc., New York, USA) was used for data analysis. All data are expressed as mean \pm SD (standard deviation). Paired two-tailed $t$-test or chi-square test was used for comparing differences between two groups. $P<0.05$ was considered statistically significant.

\section{RESULTS}

\section{Oxymatrine treatment blocked the proliferative and migratory activities of $\mathrm{BCa}$}

MDA-MB-231 and TB549 cells were induced with 10 , 50 or $100 \mu \mathrm{M}$ oxymatrine for $24 \mathrm{~h}$, respectively. Results from MTT assay revealed that the proliferative rate was dose-dependently reduced in $\mathrm{BCa}$ cells (Figure $1 \mathrm{~A}$ ). Subsequently, $\mathrm{BCa}$ cells were treated with $50 \mu \mathrm{M}$ Oxymatrine for 24, 48 or $72 \mathrm{~h}$, respectively. Results from CCK-8 assay revealed the declined viability in $\mathrm{BCa}$ cells treated with Oxymatrine compared to those of control (Figure $1 \mathrm{~B}$ and $\mathrm{C}$ ). Similarly, migratory ability of BCa cells was suppressed by oxymatrine treatment as well (Figure $1 \mathrm{D}$ and $\mathrm{E}$ ).

\section{Oxymatrine treatment downregulated miRNA- 188 in $\mathrm{BCa}$}

Relative level of miRNA-188 was dosedependently downregulated in MDA-MB-231 and TB549 cells induced with $0,10,50$ or $100 \mu \mathrm{M}$ Oxymatrine for $24 \mathrm{~h}$, respectively (Figure $2 \mathrm{~A}$ ). To uncover potential functions of miRNA-188 in $\mathrm{BCa}$, we constructed miRNA-188 inhibitor and tested its transfection efficacy (Figure $2 \mathrm{~B}$ ). Knockdown of miRNA-188 markedly elevated viability and migratory cell number in $\mathrm{BCa}$ (Figure $2 \mathrm{C}-\mathrm{E})$. It is suggested that miRNA-188 exerted an anti-tumor role in $\mathrm{BCa}$.

\section{PTEN was the direct target of miRNA-188}

Through database prediction, potential binding sequences in the promoter regions of PTEN and miRNA-188 were depicted (Figure $3 \mathrm{~A}$ ). Transfection efficacy of miRNA-188 mimics was

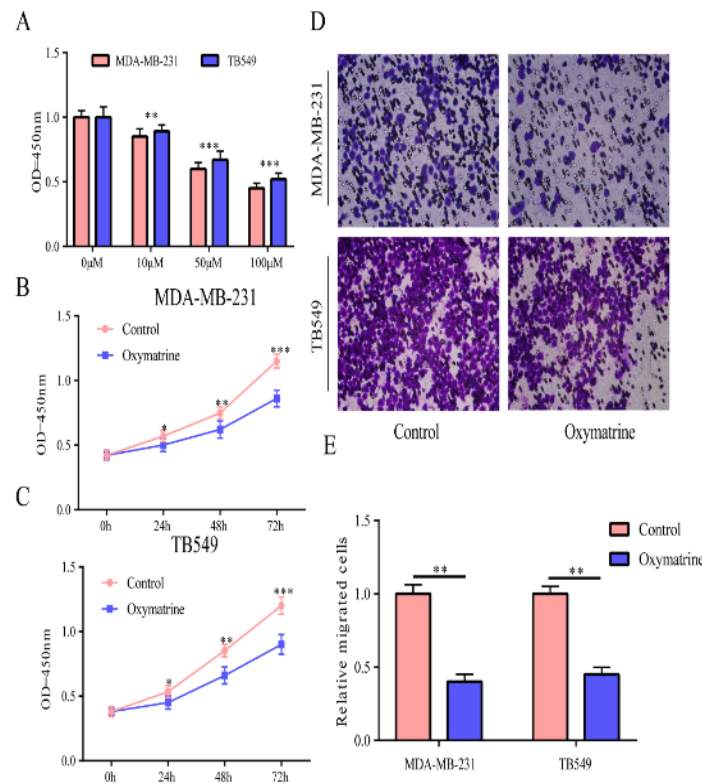

Figure 1: Oxymatrine treatment blocked proliferative and migratory abilities of $\mathrm{BCa}$. (A) Proliferative rate detected using MTT assay in MDA-MB-231 and TB549 cells treated with 10,50 or $100 \mu \mathrm{M}$ Oxymatrine for $24 \mathrm{~h}$. (B, C) Viability detected by CCK-8 assay in MDA-MB-231 and TB549 cells treated with $50 \mu \mathrm{M}$ Oxymatrine for 24,48 or 72 h. (D, E) Migration determined by Transwell assay in MDA-MB-231 and TB549 cells treated with $50 \mu \mathrm{M}$ oxymatrine for $24 \mathrm{~h}$

excellent in MDA-MB-231 and TB549 cells (Figure $3 \mathrm{~B}$ ). It is shown that luciferase activity markedly declined in $\mathrm{BCa}$ cells co-transfected with PTEN WT and miRNA-188 mimics, verifying their binding relationship (Figure $3 \mathrm{C}$ ). Moreover, the relative level of PTEN was remarkably downregulated in $\mathrm{BCa}$ cells overexpressing miRNA-188, while it was upregulated in those transfected with miRNA-188 inhibitor (Figure 3 D and $E$ ). Thus, PTEN was the direct target of miRNA-188 and its level was negatively regulated by miRNA-188.

\section{Oxymatrine treatment downregulated miRNA- 188 and upregulated PTEN in $\mathrm{BCa}$}

Interestingly, PTEN level was dose-dependently upregulated in $\mathrm{BCa}$ cells treated with increasing doses of oxymatrine (Figure 4A \& 4B). In MDAMB-231 and TB549 cells. $50 \mu \mathrm{M}$ oxymatrine markedly upregulated PTEN which was downregulated by overexpression of miRNA-188 (Figure 4C \& 4D). In addition, decreased viability in Oxymatrine-treated $\mathrm{BCa}$ cells was partially reversed by transfection of miRNA-188 mimics (Figure 4E, 4F). Therefore, it is considered that Oxymatrine treatment affected $\mathrm{BCa}$ progression by downregulating miRNA-188 to target PTEN. 
A

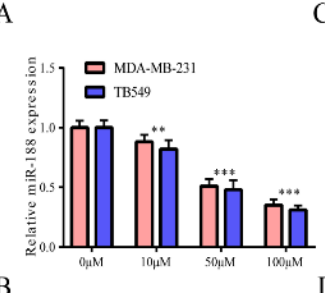

B

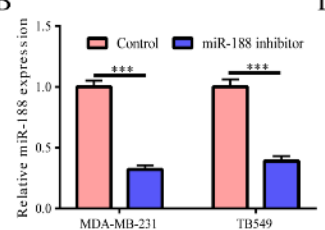

E

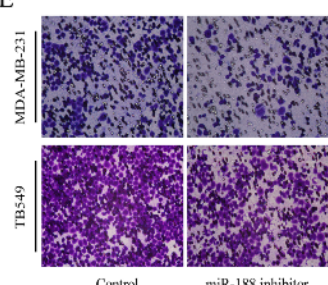

C
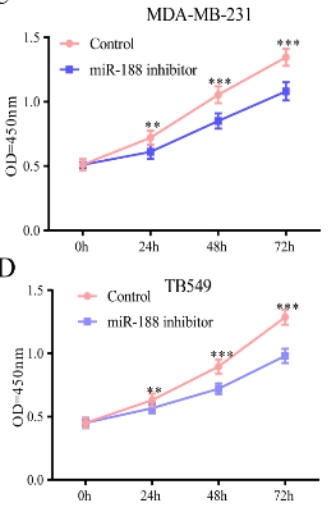

Figure 2: Oxymatrine treatment downregulated miRNA-188 in BCa. (A) MiRNA-188 level in MDA-MB231 and TB549 cells treated with $0,10,50$ or $100 \mu \mathrm{M}$ Oxymatrine for $24 \mathrm{~h}$. (B) Transfection efficacy of miRNA-188 inhibitor in MDA-MB-231 and TB549 cells. (C, D) Viability in MDA-MB-231 and TB549 cells transfected with control or miRNA-188 inhibitor. (E) Migration of MDA-MB-231 and TB549 cells transfected with control or miRNA-188 inhibitor.

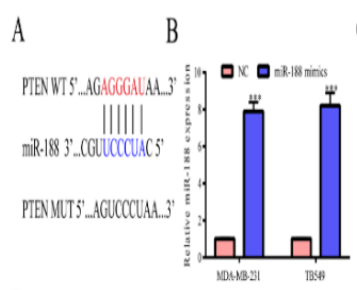

D

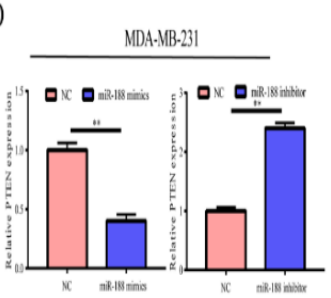

C MDA-MB-231

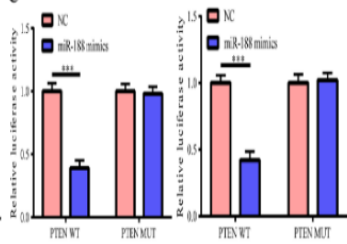

E

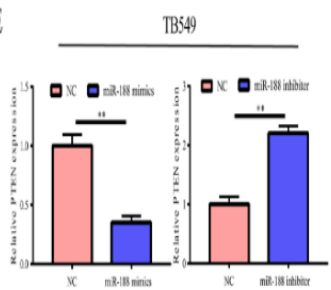

Figure 3: PTEN was the direct target of miRNA-188. (A) Binding sequences in the promoter regions of PTEN and miRNA-188. (B) Transfection efficacy of miRNA-188 mimics in MDA-MB-231 and TB549 cells. (C) Luciferase activity in MDA-MB-231 and TB549 cells co-transfected with NC/miRNA-188 mimics and PTEN WT/PTEN MUT. (D, E) PTEN level in MDA-MB231 and TB549 cells transfected with miRNA-188 mimics or inhibitor
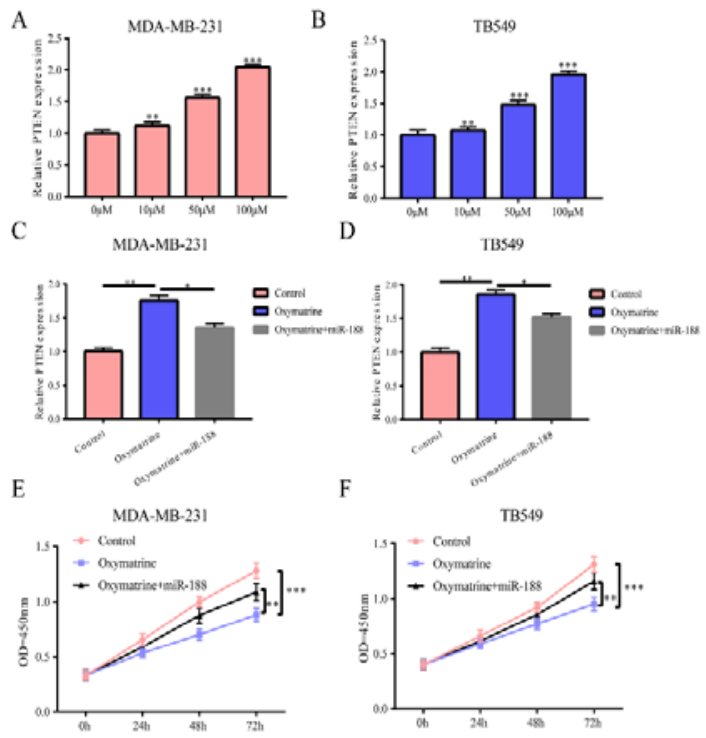

Figure 4: Oxymatrine treatment downregulated miRNA-188 and thereby upregulated PTEN in BCa. (A, B) PTEN levels in MDA-MB-231 and TB549 cells treated with $0,10,50$ or $100 \mu \mathrm{M}$ Oxymatrine for $24 \mathrm{~h}$, respectively. (C, D) PTEN levels in MDA-MB-231 and TB549 cells treated with blank control, $50 \mu \mathrm{M}$ Oxymatrine or $50 \mu \mathrm{M}$ Oxymatrine + miRNA-188 mimics. (E, F) Viability of MDA-MB-231 and TB549 cells treated with blank control, $50 \mu \mathrm{M}$ Oxymatrine or $50 \mu \mathrm{M}$ Oxymatrine + miRNA-188 mimics

\section{DISCUSSION}

Traditional Chinese Medicine is a tremendous treasure in clinical practice. Oxymatrine is extracted from the root of Sophora flavescens, which is widely distributed in Asia and Pacific Islands. Oxymatrine has been identified as the main active ingredient of Sophora flavescens and it exerts multiple biological functions. In many types of cancer, Oxymatrine presents anti-tumor properties [11-14]. For instance, oxymatrine suppresses EMT in colorectal cancer via the activation of the NF-kB pathway. By regulating the levels of Bcl-2 and Bax, oxymatrine induces apoptosis and blocks proliferation in lung cancer cells A549. The findings revealed that oxymatrine treatment downregulated miRNA-188, thus inhibiting the capacity of BCa cells to proliferate and migrate.

Changes in miRNA activities and functions are closely linked to cancer phenotypes. Molecular regulation of miRNAs is of great significance in developing cancer treatment strategies. Based on literature review, miRNA-188 is generally considered as a tumor-suppressor gene [15-17]. In the present work, miRNA-188 was downregulated in $\mathrm{BCa}$ cells following Oxymatrine treatment. Knockdown of miRNA-188 
accelerated proliferative and migratory activities in $\mathrm{BCa}$ cells. PTEN was found to be the direct target of miRNA-188 through dual-luciferase reporter gene assay. PTEN, a tumor-suppressor gene with dual-specificity phosphatase activities, is involved in the inhibition of tumor cell growth and tumorigenesis $[18,19]$. PTEN mutation is responsible for the formation of primary and metastatic malignancies [20]. This study showed that PTEN is the target of miRNA-188, and more importantly, it was involved in $\mathrm{BCa}$ progression regulated by miRNA-188.

\section{CONCLUSION}

Oxymatrine treatment mitigates $\mathrm{BCa}$ progression by downregulating the ability of miRNA-188 and upregulating PTEN. These findings provide a new strategy for the diagnosis and treatment of BCa.

\section{DECLARATIONS}

\section{Conflict of Interest}

No conflict of interest associated with this work.

\section{Contribution of Authors}

The authors declare that this work was done by the authors named in this article and all liabilities pertaining to claims relating to the content of this article will be borne by them.

\section{Open Access}

This is an Open Access article that uses a funding model which does not charge readers or their institutions for access and distributed under the terms of the Creative Commons Attribution License (http://creativecommons.org/licenses/by/ 4.0) and the Budapest Open Access Initiative (http://www.budapestopenaccessinitiative.org/rea d), which permit unrestricted use, distribution, and reproduction in any medium, provided the original work is properly credited.

\section{REFERENCES}

1. Siegel $R$, Naishadham $D$, Jemal A. Cancer statistics, 2013. CA Cancer J Clin 2013; 63(1): 11-30.

2. Jemal A, Bray F, Center MM, Ferlay J, Ward E, Forman D. Global cancer statistics. CA Cancer J Clin 2011; 61(2): 69-90.

3. Weigelt $B$, Peterse $J L$, van $T$ VL. Breast cancer metastasis: markers and models. Nat Rev Cancer 2005; 5(8): 591-602
4. Sayed $D$, Abdellatif M. MicroRNAs in development and disease. Physiol Rev 2011; 91(3): 827-887.

5. Palmero El, de Campos SG, Campos M, de Souza NC, Guerreiro ID, Carvalho AL, Marques MM. Mechanisms and role of microRNA deregulation in cancer onset and progression. Genet Mol Biol 2011; 34(3): 363-370.

6. Qadir MI, Faheem A. miRNA: A Diagnostic and Therapeutic Tool for Pancreatic Cancer. Crit Rev Eukaryot Gene Expr 2017; 27(3): 197-204.

7. Sotiropoulou G, Pampalakis G, Lianidou E, Mourelatos Z. Emerging roles of microRNAs as molecular switches in the integrated circuit of the cancer cell. Rna 2009; 15(8): 1443-1461.

8. Bertoli G, Cava C, Castiglioni I. MicroRNAs: New Biomarkers for Diagnosis, Prognosis, Therapy Prediction and Therapeutic Tools for Breast Cancer. Theranostics 2015; 5(10): 1122-1143.

9. Cava C, Bertoli G, Ripamonti M, Mauri G, Zoppis I, Della $R P$, Gilardi MC, Castiglioni I. Integration of mRNA expression profile, copy number alterations, and microRNA expression levels in breast cancer to improve grade definition. Plos One 2014; 9(5): e97681.

10. Adhami M, Haghdoost AA, Sadeghi B, Malekpour AR. Candidate miRNAs in human breast cancer biomarkers: a systematic review. Breast Cancer-Tokyo 2018; 25(2): 198-205.

11. Liu Y, Bi T, Wang Z, Wu G, Qian L, Gao Q, Shen G. Oxymatrine synergistically enhances antitumor activity of oxaliplatin in colon carcinoma through PI3K/AKT/mTOR pathway. Apoptosis 2016; 21(12): 1398-1407.

12. Liang L, Huang J. Oxymatrine inhibits epithelialmesenchymal transition through regulation of NFkappaB signaling in colorectal cancer cells. Oncol Rep 2016; 36(3): 1333-1338.

13. Liu Y, Bi T, Dai W, Wang G, Qian L, Gao Q, Shen G. Oxymatrine synergistically enhances the inhibitory effect of 5-fluorouracil on hepatocellular carcinoma in vitro and in vivo. Tumour Biol 2016; 37(6): 7589-7597.

14. Wang B, Han $Q$, Zhu $Y$. Oxymatrine inhibited cell proliferation by inducing apoptosis in human lung cancer A549 cells. Biomed Mater Eng 2015; 26 Suppl 1: S165S172.

15. Peng $Y$, Shen $X$, Jiang $H$, Chen $Z$, Wu J, Zhu $Y$, Zhou $Y$, Li J. miR-188-5p Suppresses Gastric Cancer Cell Proliferation and Invasion via Targeting ZFP91. Oncol Res 2018; 27(1): 65-71.

16. Zhang $H$, Qi S, Zhang T, Wang A, Liu R, Guo J, Wang $Y$, $X u Y$. miR-188-5p inhibits tumour growth and metastasis in prostate cancer by repressing LAPTM4B expression. Oncotarget 2015; 6(8): 6092-6104.

17. Fang $F$, Chang $R M, Y u L$, Lei $X$, Xiao S, Yang $H$, Yang LY. MicroRNA-188-5p suppresses tumor cell proliferation and metastasis by directly targeting FGF5 in hepatocellular carcinoma. J Hepatol 2015; 63(4): 874885.

18. Kechagioglou P, Papi RM, Provatopoulou X, Kalogera E, Papadimitriou E, Grigoropoulos $P$, Nonni A, Zografos G,

Trop J Pharm Res, November 2021; 20(11): 2271 
Kyriakidis DA, Gounaris A. Tumor suppressor PTEN in breast cancer: heterozygosity, mutations and protein expression. Anticancer Res 2014; 34(3): 1387-1400.

19. Jefferies $M T$, Cox $A C$, Shorning $B Y$, Meniel $V$, Griffiths $D$, Kynaston HG, Smalley MJ, Clarke AR. PTEN loss and activation of K-RAS and beta-catenin cooperate to accelerate prostate tumourigenesis. J Pathol 2017; 243(4): 442-456.

20. Kechagioglou P, Papi RM, Provatopoulou X, Kalogera E, Papadimitriou E, Grigoropoulos $P$, Nonni A, Zografos $G$, Kyriakidis DA, Gounaris A. Tumor suppressor PTEN in breast cancer: heterozygosity, mutations and protein expression. Anticancer Res 2014; 34(3): 1387-1400. 